\title{
Perceived Importance and Enjoyment of Sexuality in Late Midlife: Cohort Differences in the Longitudinal Aging Study Amsterdam (LASA)
}

\author{
Karolina Kolodziejczak $^{1}$ (D) - Johanna Drewelies ${ }^{1}$ • Dorly J. H. Deeg ${ }^{2}$ - Martijn Huisman ${ }^{2,3}$ • Denis Gerstorf ${ }^{1,4}$
}

Published online: 11 September 2020

(C) The Author(s) 2020

\begin{abstract}
Introduction Age-related declines in multiple facets of sexuality in later life are well documented. However, most studies have been cross-sectional with data collected at one point in time, leaving questions about cohort differences and interrelated historical changes in physical health and psychosocial functioning unanswered.

Methods We examined cohort differences in perceived importance and enjoyment of sexuality in late midlife using data from the Longitudinal Aging Study Amsterdam (LASA) obtained 20 years apart, 1992-1993 $(N=718)$ and 2012-2013 $(N=860)$, from two independent samples aged 55 to 65 years (both samples: $M_{\text {age }} \approx 60,52-53 \%$ women).

Results Later-born adults in late midlife reported attributing slightly higher importance to sexuality than their earlier-born peers and experiencing their sex life as slightly less pleasant. Effect sizes were small at the sample level $(d<.15)$, but substantial for certain population segments. For example, historical increases in reported importance of sexuality were especially pronounced among women with no partner $(d=.56)$. When controlling for socio-demographic, physical health, and psychosocial factors, cohort differences in perceived importance of sexuality remained significant, but those for enjoyment did not.

Conclusions Late-midlife sexuality undergoes historical changes. Specifically, reported perceived importance of sexuality has increased over historical time, especially in particular population segments.

Policy implications We discuss whether our findings represent historical changes in actual behavior, perception, or the willingness to report on one's sex life.
\end{abstract}

Keywords Sexuality $\cdot$ Middle age $\cdot$ Old age $\cdot$ Cohort differences $\cdot$ Historical change

\section{Introduction}

Over the past decade, sexuality in midlife and old age has received increased attention (Buczak-Stec et al., 2019;

Electronic supplementary material The online version of this article (https://doi.org/10.1007/s13178-020-00486-2) contains supplementary material, which is available to authorized users.

Karolina Kolodziejczak

karolina.kolodziejczak@hu-berlin.de

1 Department of Psychology, Humboldt University Berlin, Unter den Linden 6, 10099 Berlin, Germany

2 Department of Epidemiology and Data Science, Amsterdam Public Health Research Institute, Amsterdam UMC, Vrije Universiteit Amsterdam, Amsterdam, the Netherlands

3 Department of Sociology, Vrije Universiteit Amsterdam, Amsterdam, the Netherlands

4 Department of Human Development and Family Studies, Pennsylvania State University, State College, PA, USA
Karraker et al., 2011; Orr et al., 2017). A number of studies converge in suggesting that several aspects of sexuality show on average age-related decrements, but a considerable proportion of adults continue having an active sex life into advanced ages (Kolodziejczak et al., 2019; Schick et al., 2010). However, previous empirical reports were typically based on cross-sectional data collected at one specific point in time (e.g., Lee et al., 2016). Thus, they did not allow disentangling age-related differences from those associated with the historical times people were born and living in. Given that sexuality is considerably shaped by historical and social circumstances (Pettit \& Hegarty, 2014), it stands to reason that attitudes toward sexuality differ across historical time and contribute to the occurrence of cohort differences in sexual behaviors and experiences (Mercer et al., 2013; Twenge et al., 2017). Additionally, historical changes in several life domains in late midlife that are closely intertwined with sexual functioning such as lower levels of loneliness (Suanet \& van Tilburg, 2019) and higher levels of internal control among later-born cohorts (Gerstorf et al., 2019) might have allowed later-born 
generations to perceive sexuality differently, compared with their earlier-born peers. Thus, in the current study, we examined cohort differences in two aspects of late-midlife sexuality: the importance people attribute to sexuality and the extent to which they experience their sex life as pleasant. We also accounted for a comprehensive number of socio-demographic, physical health, and psychosocial correlates that are known to differ between individuals and across historical time (Drewelies et al., 2018; Galenkamp et al., 2016) and tested interactions between these and cohort membership to explore if the historical changes examined have been more pronounced in particular population segments than others. To do so, we made use of data from two independent adult samples aged 55 to 65 years (both samples: $M_{\text {age }} \approx 60,52-53 \%$ women) obtained 20 years apart: in 1992-1993 $(N=718)$ and 2012-2013 $(N=860)$ in the Longitudinal Aging Study Amsterdam (LASA; Hoogendijk et al., 2016; Huisman et al., 2011).

\section{Importance and Enjoyment of Sexuality in Late Midlife}

Midlife is a life phase characterized by several unique developmental transitions (Infurna et al., 2020) that are presumably also relevant for experiencing one's sexuality. To illustrate, the menopausal transition may constitute a challenge for sexual functioning (Avis et al., 2017). In a similar vein, late midlife is assumed to be the period of life of increasing risk of health problems (e.g., disease onset), and poor health has been repeatedly shown to be related to poor sexual functioning among adults aged 50 and older (Lee et al., 2016). On the other hand, sexuality remains for many adults a valuable aspect of life until old age, and a fulfilling sex life in older age is linked with indicators of successful aging (Buczak-Stec et al., 2019; Štulhofer et al., 2018). Late midlife may thus be a critical period for maintaining a (satisfying) sex life into old age.

In this study, we focused on two aspects of sexuality: perceived importance of sexuality and enjoyment of sex life, both crucial for a better understanding of individual differences in late-midlife sexuality. The importance people attribute to sexuality reflects the role and value of sex in people's current lives (Gott \& Hinchliff, 2003). Previous studies have suggested that, for a considerable number of adults, sexuality remains a valuable aspect of life into old age (Laumann et al., 2006; Müller et al., 2014) and plays an important role, for example, for fostering intimacy in one's partnership, experiencing sexual pleasure or vitality (Fileborn et al., 2017; Ševčíková \& Sedláková, 2020). Importance attributed to sexuality is closely intertwined with other key aspects of sexuality, including sexual activity, sexual desire, and sexual satisfaction (DeLamater \& Sill, 2005; Thomas et al., 2015), and presumably also with other areas of functioning. For example, higher within-couple discrepancy in the importance attributed to sex in middle and older age is related to more pronounced relationship strain (Orr et al., 2017). Of note is that numerous studies have inferred the importance of sexuality in later life from the frequency of sexual activity reported by study participants. However, such operational definition is questionable, for example, because of the interest-activity gap (Pfeiffer et al., 1969), which indicates that sexual interest in later life often exceeds actual sexual activity (Beier et al., 2019). Thus, empirical research should aim at using more direct measures of the importance people attribute to sexuality.

Enjoyment of sexuality reflects the degree to which people experience their sex life as pleasurable. Such enjoyment refers to people's idiosyncratic definition of a fulfilling sex life and conveys information about the quality of sexual experience (Fileborn et al., 2017). Enjoyment of sex has been linked with other important aspects of sexuality such as sexual desire (DeLamater \& Sill, 2005) and related constructs such as sexual satisfaction are expected to be beneficial for other areas of functioning such as overall subjective well-being (BuczakStec et al., 2019). Examining enjoyment thus complements earlier empirical reports by moving beyond considering mere quantitative aspects of sexuality, such as the frequency of sexual activity.

\section{Cohort Differences in Late-Midlife Sexuality}

Life course sociology and lifespan psychology have long noted that individual functioning and development are profoundly shaped by the historical and socio-cultural contexts people are living in (Baltes et al., 1979; Bronfenbrenner, 1993; Elder Jr., 1974; Schaie, 1965). Acknowledging that sexual functioning is shaped by biological, psychological, and social factors (DeLamater, 2012), societal contexts and historical changes therein have presumably also formed and affected people's experiences and perceptions of sexuality. Three sets of historical shifts over the past decades may have particularly contributed to changes in perception of sexuality in later life nowadays.

First, the sexual revolution of the late 1960s and early 1970s might have particularly impacted adolescents and young adults at that time (Forbes et al., 2017) and profoundly shaped their identity-relevant attitudes and values (Duncan \& Agronick, 1995; Stewart \& Healy, 1989). The movement has spread more liberal attitudes toward sexuality that facilitated engagement with sex life. In a similar vein, the Gay Rights movement of the 1970s is often thought of as having had society-wide effects that profoundly shaped how people think about sexuality (Shield, 2020). Assuming that such attitudes continue to be relevant today (DeLamater, 2012), we hypothesized that cohorts born after the Second World War value and enjoy their sex lives in late midlife more than earlier-born cohorts. Second, feminist societal movements in the 1960s 
have broadened the debate on gender equality and promoted, among other things, sexual self-determination and sexual pleasure among women (Rubin, 1998). This, in turn, has contributed to the popularization of the birth control pill, which provided more reproductive autonomy to women (Liao \& Dollin, 2012). Women have increasingly entered the labor market, which forced changes in family models and the division of labor in couples (Shockley \& Shen, 2015). Following Baumeister's (2000) notion of gender differences in erotic plasticity suggesting that female sexuality is more responsive to social circumstances and situational factors than male sexuality, one could infer that the overall more permissive sexual climate of the 1960s and 70s has particularly affected women at that time (see also Duncan \& Agronick, 1995). As a consequence, we hypothesized that historical shifts in the perceived importance and enjoyment of sexuality are probably more pronounced among women than among men, with later-born women in late midlife reporting higher importance and more enjoyment of sexuality than earlier-born same-aged women.

Third, more recent developments such as medical advancements over the past decades can also be expected to have shaped late-midlife sexuality. Such changes encompass increases in treatments of sexual dysfunction both in women (e.g., hormonal replacement therapy used also for dyspareunia due to vaginal dryness or loss of libido; Sarrel, 2000) and men (e.g., sildenafil for erectile dysfunction; Goldstein et al., 1998). To illustrate, Viagra ${ }^{\circledR}$ entered the US market in the late 1990s and 10 years later annual sales reached almost two billion USD (Pfizer Inc, 2010). Better sexual functioning presumably facilitates perceiving sexuality as important and engaging with sex life into old age. Likewise, easy access to medication that improves sexual function might contribute to a more pleasurable sex life. At the same time, the efforts and finances invested into maintaining sexual functions such as purchasing Viagra ${ }^{\circledR}$ likely mirror the importance midlife and older adults attribute to their sex life. Thus, this relationship might be bidirectional.

Empirically, studies examining historical trends in sexuality have indeed reported cohort differences on its several dimensions. Specifically, later-born adults presumably remain sexually active until older age: Beckman, Waern, Östling, Sundh, and Skoog (2014) reported that a higher percentage of later-born Swedish 70-year-olds engage with sex life today compared with their same-aged peers 20 years ago. Another study on adults in the US has shown historical decreases in the frequency of sexual activity among those in their $50 \mathrm{~s}$, but no decline among those over 60 (Twenge et al., 2017). Later-born cohorts of older adults have also been found to report more positive attitudes to sexuality, higher satisfaction with sexuality, and fewer sexual dysfunctions than earlier-born cohorts (Beckman et al., 2008). Very few studies though have specifically targeted adults in late midlife to examine cohort differences in sexuality. In particular, Forbes et al. (2017) have examined perceived quality of sexual aspects of life (i.e., sexual frequency, number of sexual partners, perceived control over as well as thought and effort put into sex life) among US adults in late midlife, interviewed in 1995 and 2013. Their results provided no evidence for historical changes in these aspects of sexuality. In our report, we capitalize on conceptual accounts and earlier empirical studies and investigate cohort differences in perceived importance and enjoyment of sex life as further indicators of historical change in late-midlife sexuality.

\section{The Role of Socio-Demographic, Physical Health, and Psychosocial Factors}

We speculate that perceived importance and enjoyment of sexuality in late midlife have increased over historical time also because of changes that emerged in socio-demographic, physical health, and psychosocial functioning. Moreover, drawing from previous works on cohort differences (e.g., Drewelies et al., 2018), we hypothesize that historical changes in sexuality might have been particularly pronounced in certain subgroups of the population, but not others. In the following, we consider several individual and cohort differences that may be particularly relevant for perceived importance and enjoyment of sexuality in late midlife.

To begin with, older age is a known risk factor for declines in sexual activity (e.g., Karraker et al., 2011). Gender differences in later-life sexuality have also been well documented, with older men reporting higher importance of sexuality and having a lower risk of sexual dissatisfaction than older women (Laumann et al., 2006; Müller et al., 2014; Syme et al., 2012). Also, later-born cohorts have experienced more years of formal education (Drewelies, Deeg, et al., 2018). Better educated older adults may hold less negative attitudes toward sexuality (DeLamater \& Sill, 2005), which may correspond to higher importance and enjoyment of sexuality. Religiosity, in turn, may have a prohibitive role for sexual activity in unmarried older adults, especially among women (McFarland et al., 2011), which may result in attributing lower importance to sexuality among those individuals perceiving religion as more salient. It remains to be seen how salience of religion relates to enjoyment of sexuality.

Physical health problems may be experienced as a barrier for having sex, which in turn may undermine the importance people attribute to sexuality (Gott \& Hinchliff, 2003). Recent reports have documented that the numbers of diagnosed illnesses in late midlife are currently on the rise (e.g., for diagnosed cancer, diabetes, or stroke), and provided mixed results on cohort differences in functional limitations (Crimmins et al., 2019; Hoeymans et al., 2012). However, it remains unclear whether and how these cohort differences in health relate to sexuality. There is initial evidence that health problems impact sexuality among later-born older adults less, 
comparing to the earlier-born cohorts (Beckman et al., 2014). In the current report, we will test how multimorbidity and functional limitations relate to historical changes in the importance and enjoyment of sexuality among adults in late midlife.

For psychosocial resources, having a partner has repeatedly been found to be crucial for sexuality in old age, particularly for women (Kolodziejczak et al., 2019; Schick et al., 2010). Twenge et al. (2017) reported historical declines in sexual activity in the USA partially due to increased numbers of adults having no partner. In line with previous findings, we expected that having a partner is related to attributing higher importance to sexuality (Gott \& Hinchliff, 2003). However, it remains unclear whether partner status relates to enjoyment of sexuality. Apart from partner status, acknowledging that greater social embeddedness is associated with more sexual interest in later life (Iveniuk \& Waite, 2018), we expect that historically lower levels of loneliness, especially among divorced adults in late midlife (Van Tilburg et al., 2014), go hand in hand with perceiving sexuality as more important among adults in late midlife.

Depressive symptoms have repeatedly been found to undermine sexuality, possibly because of general lack of interest in and pleasure derived from different activities (Bach et al., 2013). Finally, perceived constraints might undermine sexuality because believing that one has little control over one's life may indeed stand in the way of taking any action toward fulfilling one's (sexual) desires. We assumed that historical shifts toward fewer perceived constraints among adults in late midlife (e.g., Drewelies, Deeg, et al., 2018) have contributed to the presumed historical increases in the perceived importance and, to some degree, enjoyment of sexuality.

\section{The Present Study}

In our study, we drew from earlier reports about historical changes in key aspects of sexuality in later life (e.g., Beckman et al., 2014; Forbes et al., 2017; Twenge et al., 2017) and extended those to specifically consider the importance and enjoyment of sexuality among adults in late midlife. Because many societal trends evolve gradually over time, one can expect developmentally relevant societal conditions to differ more strongly from one another the further away the historical times are that people have experienced and lived in when being at the same or comparable phases of their lives (Drewelies et al., 2019). There is empirical evidence implying that a time window of about 20 years may allow for historical changes in psychosocial functioning to emerge (e.g., Drewelies, Deeg, et al., 2018; Hülür et al., 2016). Thus, we investigated mean-level differences between two samples in perceived importance of sexuality and the enjoyment of one's sex life and examined the socio-demographic, physical health, and psychosocial correlates of both aspects of sexuality, as well as their interactions with cohort membership to account for domain-specific cohort differences.

\section{Method}

Detailed information about participants, variables, and data collection procedures can be found in previous publications (Hoogendijk et al., 2016; Huisman et al., 2011) and online (Lasa-vu.nl, 2020). Selected details relevant for our report are noted below.

\section{Participants and Procedure}

The LASA is a prospective longitudinal study of middle-aged and older adults in the Netherlands, examining a wide range of physical, cognitive, emotional, and social aspects of functioning in the aging population (Huisman et al., 2011). Study participants were recruited from municipal registries in three, both urban and rural regions of the Netherlands, selected to optimally represent the Dutch older adult population.

The first LASA cohort included adults aged 55 to 85 years (born between 1908 and 1937), with older men and the oldest participants being oversampled. Sixty-two percent of contacted eligible persons completed the pre-initial Living Arrangements and Social Networks (LSN) interview $(n=$ 3805), from which 3107 took part in the main LASA-I interview in 1992-1993 (Deeg et al., 2002). Of those, 966 participants (born between 1928 and 1937) were 55 to 65 years old. The third LASA cohort examined adults aged 55 to 65 years (born between 1948 and 1957). Of the contacted persons, 63\% completed the interview, resulting in a sample size of 1023 participants (Hoogendijk et al., 2016). Eligible for inclusion in this report were participants aged 55 to 65 years who provided data on at least one of two sexuality measures of interest. From the first LASA cohort, our eligibility criteria led to 718 participants ( $73 \%$ of the eligible sample) that we have included in the earlier-born cohort $\left(M_{\text {age }}=60.29, S D_{\text {age }}=2.84 ; 53 \%\right.$ women; $82 \%$ in a relationship). From the third LASA cohort, we included 860 participants ( $84 \%$ of the eligible sample) in the later-born cohort $\left(M_{\mathrm{age}}=60.38, S D_{\mathrm{age}}=2.92 ; 52 \%\right.$ women; $82 \%$ in a relationship).

Sample selectivity analyses revealed that, in both cohorts, participants who provided data on the sexuality items of interest and were thus included in our analyses $(N=718$ and $N=$ 860 , respectively) did not significantly differ from those who were not included ( $N=270$ and $N=163$, respectively) on age, gender, partner status, comorbidity, functional limitations, and depressive symptoms. In the earlier-born LASA cohort, included participants were slightly more educated $(M=9.64$, $S D=3.21$ vs. $M=8.88, S D=3.46, F(1,985)=10.63$, $\left.R^{2}=.011\right)$, reported lower salience of religion $(12 \%$ vs. $\left.21 \%, F(1,779)=4.29, R^{2}=.005\right)$ and fewer perceived 
constraints $(M=11.87, S D=3.29$ vs. $M=12.52, S D=3.55, F$ $(1,969)=7.08, R^{2}=.007$; all $\left.p \mathrm{~s}<.05\right)$ than those who were not. In the later-born cohort, there were no significant differences in education, religiosity, and perceived constraints. Descriptive information for both samples included in the study is provided in Table 1.

Data on sexuality measures of interest were available from the baseline assessment for each LASA cohort. Data on sexuality and salience of religion were collected via selfadministered questionnaires; data on all other correlates used in this study were obtained as a part of the main face-to-face interview at participants' homes. The assessment procedures and all measures used here were identical for both samples.

\section{Measures}

Sexuality Two indicators of sexuality were assessed, each with a single item. The perceived importance of sexuality was assessed using the item "How important is sexuality for you now?", answered on a five-point Likert scale ranging from very unimportant (1) to very important (5). Enjoyment of sexuality was assessed using the item "How do you experience your sex life now?", answered on a five-point Likert scale ranging from very unpleasant (1) to very pleasant (5). An additional response category for the latter item was "not applicable."

Cohort Cohort membership was treated as a dichotomous variable, contrasting those born between 1928 and 1937 who had provided data in 1992-1993 as the earlier-born cohort (0) with those born between 1948 and 1957 who had provided data in 2012-2013 as the later-born cohort (1).

Correlates As socio-demographic factors, age was calculated in years from the exact date of birth until the date of data collection. Gender was assessed as a dichotomous variable ( $0=$ woman, $1=$ man). Education was indexed as years of formal schooling. Salience of religion was derived from the questionnaire asking about important aspects in one's life. Participants were asked to indicate three out of nine aspects of life listed (including, for example, strong faith, good income, and good physical health) that they consider most important to them (Deeg, 2007). Using this information, we constructed a dichotomous variable, with those endorsing strong faith as one of the most important aspects of life (1) vs. not (0).

As physical health indicators, multimorbidity was indexed by the number of self-reported chronic illnesses from a list of eight medical conditions: heart disease, peripheral arterial disease, diabetes, chronic obstructive lung disease, cancer, osteoarthritis, rheumatoid arthritis, and stroke. A higher multimorbidity score (0-8) indicated more co-occurring illnesses reported by the participant. Functional limitations were based on self-reports for three activities expected to capture mild levels of functional limitation: (a) walking up and down a staircase of 15 steps without resting, (b) using public or one's own transportation, and (c) cutting one's own toenails (Kriegsman et al., 1997). For each activity, participants were asked if they were able to perform the activity without difficulty (0) or not (1). For our report, we calculated a mean score across the three activities, ranging from 0 (no difficulties) to 3 (all with difficulty), Cronbach's alpha $=.67 / .68$ (earlier-born/ later-born cohort, respectively; all alpha values acceptable, Cronbach, 1951; Tavakol \& Dennick, 2011).

As psychosocial variables, partner status was assessed by asking participants whether they have a partner (inside or outside the household; 1 ) or not $(0)$. The large majority of partnered participants were co-residing with the partner $(n=1241)$. In the small subgroup of participants not coresiding with the partner $(n=51)$, living-apart-together was the most common case (de Jong Gierveld, 2004). Loneliness was assessed using an 11-item scale (de Jong Gierveld \& Kamphuis, 1985; de Jong Gierveld \& van Tilburg, 1999) capturing emotional (perceived lack of close, intimate relationships; e.g., "I miss having a really close friend") and social aspects of loneliness (lack of a broader social network; e.g., "there are plenty of people I can rely on when I have problems"), each answered as yes (1) vs. no (0), Cronbach's alpha $=.87 / .88$. Depressive symptoms were measured using the Center for Epidemiologic Studies Depression Scale (CES-D; Radloff, 1977). The 20 items (e.g., "I felt sad") referenced the past week and were answered on a 4-point scale ranging from rarely or never (0) to mostly or always (3), Cronbach's alpha $=.88 / .89$. Finally, perceived constraints were measured with five negatively framed items selected from the Pearlin Mastery Scale (Pearlin \& Schooler, 1978; e.g., "there is little I can do to change many of the important things in my life"), rated on a 5-point scale ranging from strongly disagree (1) to strongly agree (5), Cronbach's alpha $=.74 / .76$.

\section{Statistical Procedure and Data Analysis}

To examine our research questions, we proceeded in two steps. In a first step, we examined mean-level differences between the two cohorts separately on (a) perceived importance and (b) enjoyment of sexuality using one-way ANOVA. In a second step, we conducted hierarchical regression analyses separately for the two sexuality measures to examine the predictive effect of cohort membership while accounting for a number of further correlates. We particularly aimed at examining the unique predictive effect of psychosocial factors, over and above the well-documented socio-demographic and health correlates of late-midlife sexuality. Thus, the stepwise sequence of models tested was as follows: cohort membership (model 1), age, gender, education (model 2), salience of 
Table 1 Descriptive Statistics and Intercorrelations of Variables under Study, Separately for the Two Cohorts

\begin{tabular}{|c|c|c|c|c|c|c|c|c|c|c|c|c|c|c|}
\hline \multirow[b]{2}{*}{ Variables (range) } & \multirow[b]{2}{*}{$M_{1992-1993}$} & \multirow[b]{2}{*}{$S D_{1992-1993}$} & \multicolumn{12}{|c|}{ Intercorrelations } \\
\hline & & & 1 & 2 & 3 & 4 & 5 & 6 & 7 & 8 & 9 & 10 & 11 & 12 \\
\hline $\begin{array}{l}\text { 1. Importance of } \\
\text { sexuality }(1-5)\end{array}$ & 3.08 & 1.03 & & $.41 * *$ & -.03 & $.29 * *$ & $.08^{*}$ & -.02 & $-.17 * *$ & $-.17 * *$ & $.27 * *$ & $-.09 *$ & $-.14 * *$ & $-.16^{* *}$ \\
\hline $\begin{array}{l}\text { 2. Enjoyment of } \\
\text { sexuality }(1-5)\end{array}$ & 3.71 & 0.82 & $.50 * *$ & & -.04 & $.13 * *$ & $.09^{*}$ & .06 & $-.15 * *$ & $-.19 * *$ & $.11^{* *}$ & $-.20 * *$ & $-.22 * *$ & $-.17 * *$ \\
\hline $\begin{array}{l}\text { 3. Age } \\
(54.79-65.55)\end{array}$ & 60.29 & 2.84 & $-.14 * *$ & -.08 & & .02 & -.05 & -.03 & $.08^{*}$ & $.07^{*}$ & -.01 & .00 & -.05 & -.04 \\
\hline 4. Men $(0,1)$ & 0.47 & 0.50 & $.33^{* *}$ & $.16^{* *}$ & .00 & & $.10 * *$ & -.02 & $-.10^{* *}$ & $-.07^{*}$ & $.12 * *$ & .06 & $-.14 * *$ & $-.09 * *$ \\
\hline $\begin{array}{l}\text { 5. Education } \\
(5-18)\end{array}$ & 9.64 & 3.21 & $.11^{* *}$ & .07 & $-.08^{*}$ & $.26 * *$ & & $-.07^{*}$ & $-.13 * *$ & $-.17^{* *}$ & -.02 & -.02 & $-.08 *$ & $-.19 * *$ \\
\hline $\begin{array}{l}\text { 6. Salience of } \\
\text { religion }(0,1)\end{array}$ & 0.12 & 0.33 & -.02 & .04 & .03 & -.06 & -.06 & & -.04 & -.04 & .02 & .00 & -.07 & $.10 * *$ \\
\hline $\begin{array}{l}\text { 7. Multimorbidity } \\
(0-8)\end{array}$ & 1.08 & 1.02 & $-.10 *$ & -.07 & $.13 * *$ & $-.09 *$ & $-.07 *$ & -.01 & & $.39 * *$ & $-.11 * *$ & $.11^{* *}$ & $.23 * *$ & $.17 * *$ \\
\hline $\begin{array}{l}\text { 8. Functional } \\
\text { limitations } \\
(0-3)\end{array}$ & 0.25 & 0.61 & $-.17 * *$ & $-.10 *$ & $.09 *$ & -.01 & $-.08^{*}$ & .00 & $.33 * *$ & & $-.10 * *$ & $.24 * *$ & $.29 * *$ & $.27 * *$ \\
\hline 9. Partnered $(0,1)$ & 0.82 & 0.38 & $.34 * *$ & .05 & $-.08^{*}$ & $.14 * *$ & .07 & .00 & -.03 & $-.08^{*}$ & & $-.34 * *$ & $-.28 * *$ & $-.13 * *$ \\
\hline $\begin{array}{l}\text { 10. Loneliness } \\
(0-11)\end{array}$ & 1.59 & 2.29 & $-.14 * *$ & $-.20 * *$ & .04 & -.01 & -.03 & -.04 & $.14 * *$ & $.14 * *$ & $-.32 * *$ & & $.45^{* *}$ & $.37 * *$ \\
\hline $\begin{array}{l}\text { 11. Depressive } \\
\text { symptoms } \\
(0-48)\end{array}$ & 6.96 & 7.28 & $-.14 * *$ & $-.14 * *$ & .00 & $-.13 * *$ & -.07 & .00 & $.20 * *$ & $.27^{* *}$ & $-.21 * *$ & $.51 * *$ & & $.52 * *$ \\
\hline $\begin{array}{l}\text { 12. Perceived } \\
\text { constraints } \\
(5-25)\end{array}$ & 11.87 & 3.29 & $-.13 * *$ & $-.18^{* *}$ & .05 & $-.09 *$ & -.06 & .01 & $.16^{* *}$ & $.18^{* * *}$ & $-.09 *$ & $.33 * *$ & $.44 * *$ & \\
\hline $\begin{array}{l}M_{2012-2013} \\
S D_{2012-2013}\end{array}$ & & & $\begin{array}{l}3.21 \\
0.88\end{array}$ & $\begin{array}{l}3.61 \\
0.81\end{array}$ & $\begin{array}{r}60.38 \\
2.92\end{array}$ & $\begin{array}{l}0.48 \\
0.50\end{array}$ & $\begin{array}{r}11.70 \\
3.41\end{array}$ & $\begin{array}{l}0.09 \\
0.28\end{array}$ & $\begin{array}{l}1.55 \\
1.27\end{array}$ & $\begin{array}{l}0.44 \\
0.79\end{array}$ & $\begin{array}{l}0.82 \\
0.39\end{array}$ & $\begin{array}{l}1.45 \\
2.26\end{array}$ & $\begin{array}{l}7.22 \\
7.02\end{array}$ & $\begin{array}{r}11.32 \\
3.16\end{array}$ \\
\hline
\end{tabular}

Note. $N=1578\left(N_{1992-1993}=718 ; N_{2012-2013}=860\right)$. Descriptive statistics and intercorrelations for the earlier-born cohort (born between 1928 and 1937 , data obtained in 1992-1993) are presented below the diagonal, for the later-born cohort (born between 1948 and 1957, data obtained in 2012-2013) above the diagonal. $M=$ mean, $S D=$ standard deviation. Age and education in years

$* p<.05$

$* * p<.01$

religion (model 3), multimorbidity, functional limitations (model 4), relationship status, loneliness (model 5), depressive symptoms, and perceived constraints (model 6). When analyzing the enjoyment of sexuality item, we excluded participants who used the "not applicable" response category $(n=$ 305 in total).

Additionally, acknowledging gender differences in how being partnered or not is associated with sexuality in later life (Kolodziejczak et al., 2019), we explicitly tested the interaction of gender and relationship status and the three-way interaction with cohort membership, including the corresponding lower-order interactions. Also, we exploratory tested the quadratic term for age as well as two-way and higher-order interactions of cohort membership with correlates included in a stepwise manner, separately for importance and enjoyment of sexuality. Of those explored interactions, we trimmed all non-significant cohort interactions for parsimony (Grimm et al., 2016). The final model (model 6) includes each the aforementioned two- and three-way cohort interactions with gender and partner status, as well as the cohort interactions that occurred significant at $p<.01$ 
level and respective lower-order interactions. Age was centered at 60 years, and all other predictors were centered at the mean of the total sample. Analyses were conducted using the SAS 9.4 software.

\section{Results}

Table 1 shows descriptive statistics and intercorrelations of the variables under study. Three aspects are of note. First, importance and enjoyment of sexuality were moderately correlated in both samples ( $r=.50$ for the earlier-born, and $r=.41$ for the later-born LASA cohort, both $p s<.01$ ), indicating that the two cover in part different aspects of the larger measurement space of sexuality. Second, both sexuality measures exhibited small to moderately sized associations with the correlates included, suggesting that the correlates represent a wide range of relevant background factors. Third, in line with previous LASA reports (Drewelies, Deeg, et al., 2018; Hoogendijk et al., 2016), later-born LASA participants reported on average higher education, $F(1,1577)=149.43, p<.01, d=.65$; higher multimorbidity, $F(1,1576)=65.07, p<.01, d=.39$; more functional limitations, $F(1,1575)=28.49, p<.01$, $d=.24$; and fewer perceived constraints, $F(1,1561)=$ $11.32, p<.01, d=.22$. The percentage of partnered individuals did not differ between the two samples $(82 \%$ for both cohorts).

\section{Cohort Differences in Late-Midlife Sexuality}

One-factor ANOVAs with cohort membership as the independent variable and the measures of sexuality as the respective dependent variable indicated that cohort differences were reliably different from zero for both the importance $(F[1$, $1569]=6.85, p<.01, d=.14)$ and enjoyment of sexuality $(F$ $[1,1257]=4.89, p<.05, d=-.12)$. As can be inferred from Fig. 1, later-born adults in late midlife reported slightly higher importance of sexuality than their earlier-born peers, but they also experience their sex life as slightly less pleasant.

\section{The Role of Socio-Demographic, Physical Health, and Psychosocial Factors}

In a second step, we examined the role of the correlates for cohort differences in late-midlife sexuality. Table 2 reports results of hierarchical regression analyses for the perceived importance of sexuality. Three aspects are of note. First, the point estimate for the cohort effect has only minimally altered across the series of models and predictors included. Second, in the final model (model 6 ), being younger $(\beta=-.06, p<.01$ ), being a man $(\beta=.26, p<.01)$, reporting fewer functional limitations $(\beta=-.08, p<.01)$, having a partner $(\beta=.23, p<.01)$, and perceiving fewer constraints in one's life $(\beta=-.06$, $p<.05)$ were each and independently associated with attributing more importance to sexuality. Additionally, three statistically significant interaction effects emerged. The gender-bypartner-status two-way interaction is graphically illustrated in Fig. 2 (upper panels a and b). It can be inferred that both men and women in late midlife perceived sexuality as less important when they did not have a partner. However, for women having no partner, the difference was more prominent than for men without a partner, a large effect size for women $(d=.92)$ and a medium effect size for men $(d=.43)$. The three-way cohort-by-gender-by-partner-status interaction is also shown in Fig. 2 (lower panels $\mathrm{c}$ to $\mathrm{f}$ ) and indicates that later-born women without a partner perceived sexuality as more important, compared with earlier-born single same-aged women. That is, historical increases in the importance of sexuality were particularly pronounced among women having no partner, the effect size lies in the medium range $(d=.56)$. The last three-way cohort-by-education-by-perceived-constraints interaction indicates that historical increases in the importance of sexuality were particularly pronounced among adults in late midlife with high education and who perceive few constraints. The effect size lay in the small range $(d=.26)$.

Table 3 reports results of hierarchical regression analyses for the enjoyment of sexuality. Two aspects are of note. First, the point estimate for the cohort effect has again only minimally altered across the series of models and predictors included, but in the final model, the effect did not reliably differ from zero at the significance level $p<.05$. Second, in the final model (model 6$)$, younger age $(\beta=-.05, p<.05)$, being a man $(\beta=.14, p<.01)$, reporting higher salience of religion $(\beta=.06, p<.05)$, reporting fewer functional limitations $(\beta=$ $-.08, p<.05)$, feeling less lonely $(\beta=-.13, p<.01)$, and perceiving fewer constraints $(\beta=-.07, p<.01)$ were each and independently associated with experiencing one's sex life as more pleasant. For enjoyment of sexuality, the two-way gender-by-partner-status interaction and the same three-way interaction with cohort membership were both not statistically significant. We have not found any other two- or three-way cohort interactions that would reliably differ from zero at the significance level $p<.01$. Cohort membership and the correlates included in our models conjointly accounted for $22 \%$ of the variance in importance of sexuality and $10 \%$ in the enjoyment of one's sex life.

\section{Discussion}

The objective of this study was to examine cohort differences among adults in late midlife in (a) the importance they attribute to sexuality and (b) the enjoyment of their current sex life and to investigate further socio-demographic, physical health, and psychosocial correlates of perceived importance and enjoyment of sexuality in late midlife, as well as to account for 
Fig. 1 Cohort Differences in Perceived Importance and Enjoyment of Sexuality Among Adults in Late Midlife a Importance of Sexuality

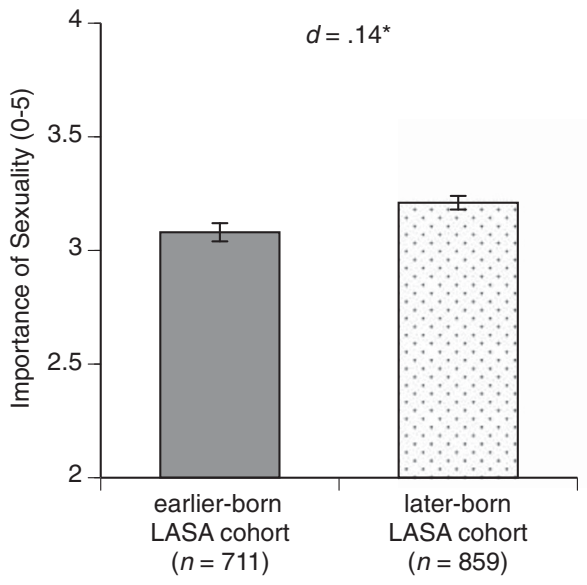

b Enjoyment of Sexuality

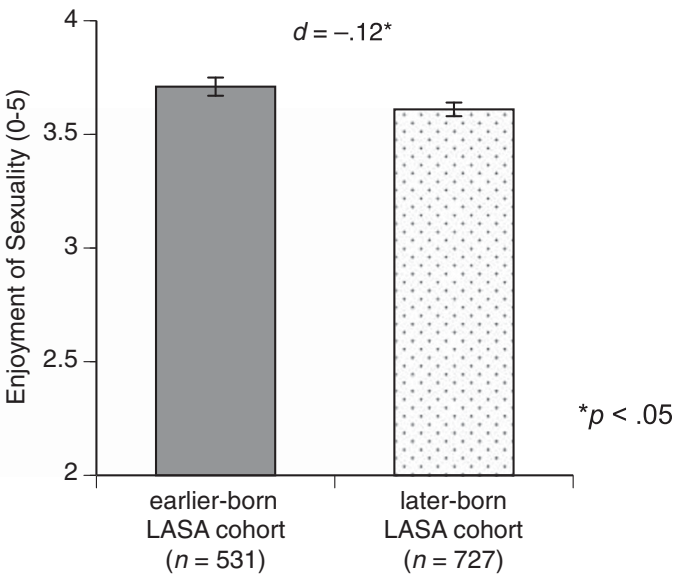

Note. Mean levels, standard errors, and effect sizes (Cohen's $d$ ) for perceived importance (left-hand panel a) and enjoyment of sexuality (right-hand panel b), separately for two LASA cohorts: those born between 1928 and 1937 (earlier-born LASA cohort; data obtained in 1992-1993) and born between 1948 and 1957 (later-born LASA cohort; data obtained in 2012-2013). The group sizes $(n s)$ are indicated in the category labels.

Table 2 Standardized Betas $(\beta)$ from Regression Analyses of Perceived Importance of Sexuality by Cohort and the Correlates

\begin{tabular}{|c|c|c|c|c|c|c|}
\hline \multirow[b]{2}{*}{ Predictors } & \multicolumn{6}{|c|}{ Importance of sexuality } \\
\hline & Model 1 & Model 2 & Model 3 & Model 4 & Model 5 & Model 6 \\
\hline Cohort & $.07 * *$ & $.06 *$ & $.06^{*}$ & $.09 * *$ & $.08 * *$ & $.06^{*}$ \\
\hline Age & - & $-.09 * *$ & $-.08 * *$ & $-.07 * *$ & $-.06^{* *}$ & $-.06^{* *}$ \\
\hline Men & - & $.31 * *$ & $.30 * *$ & $.30 * *$ & $.27 * *$ & $.26^{* *}$ \\
\hline Education & - & .04 & .04 & .01 & .03 & .02 \\
\hline Salience of religion & - & - & .00 & -.01 & -.01 & .00 \\
\hline Multimorbidity & - & - & - & $-.05^{*}$ & -.05 & -.04 \\
\hline Functional limitations & - & - & - & $-.12 * *$ & $-.10 * *$ & $-.08 * *$ \\
\hline Partnered & - & - & - & - & $.23 * *$ & $.23 * *$ \\
\hline Loneliness & - & - & - & - & -.01 & .00 \\
\hline Depressive symptoms & - & - & - & - & - & .02 \\
\hline Perceived constraints & - & - & - & - & - & $-.06^{*}$ \\
\hline Men $\times$ Partnered & - & - & - & - & $-.11 * *$ & $-.10 * *$ \\
\hline Education $\times$ Perceived constraints & - & - & - & - & - & .03 \\
\hline Cohort $\times$ Men & - & - & - & - & -.04 & -.04 \\
\hline Cohort $\times$ Education & - & - & - & - & - & .01 \\
\hline Cohort $\times$ Partnered & - & - & - & - & -.04 & -.04 \\
\hline Cohort $\times$ Perceived constraints & - & - & - & - & - & -.01 \\
\hline Cohort $\times$ Men $\times$ Partnered & - & - & - & - & $.06^{*}$ & $.06^{*}$ \\
\hline Cohort $\times$ Education $\times$ P. constraints & - & - & - & - & - & $-.07 * *$ \\
\hline Total $R^{2}$ & $<.01$ & .11 & .11 & .13 & .21 & .22 \\
\hline$F$ & $6.85^{* *}$ & $48.52 * *$ & $37.45^{* *}$ & $32.78^{* *}$ & $31.87 * *$ & $22.06^{* *}$ \\
\hline$(d f \mathrm{~s})$ & $(1,1569)$ & $(4,1569)$ & $(5,1553)$ & $(7,1550)$ & $(13,1547)$ & $(19,1531)$ \\
\hline
\end{tabular}

Note. $N=1570\left(N_{1992-1993}=711 ; N_{2012-2013}=859\right)$. Age centered at 60 years; all other predictors grand mean centered $* p<.05$

$* * p<.01$ 

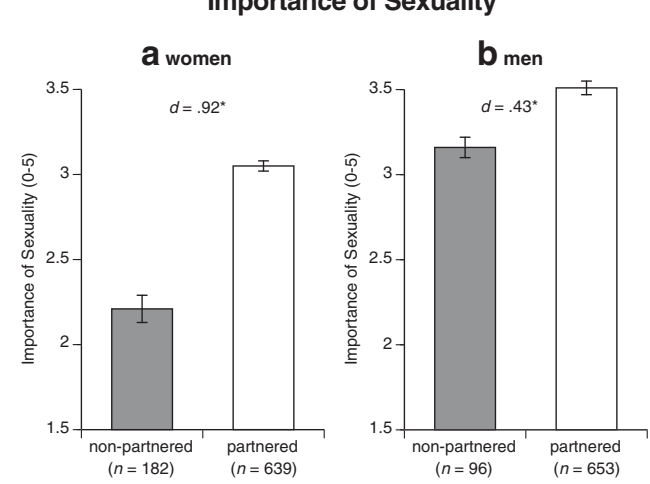

$$
{ }^{*} p<.05
$$

\section{Women}
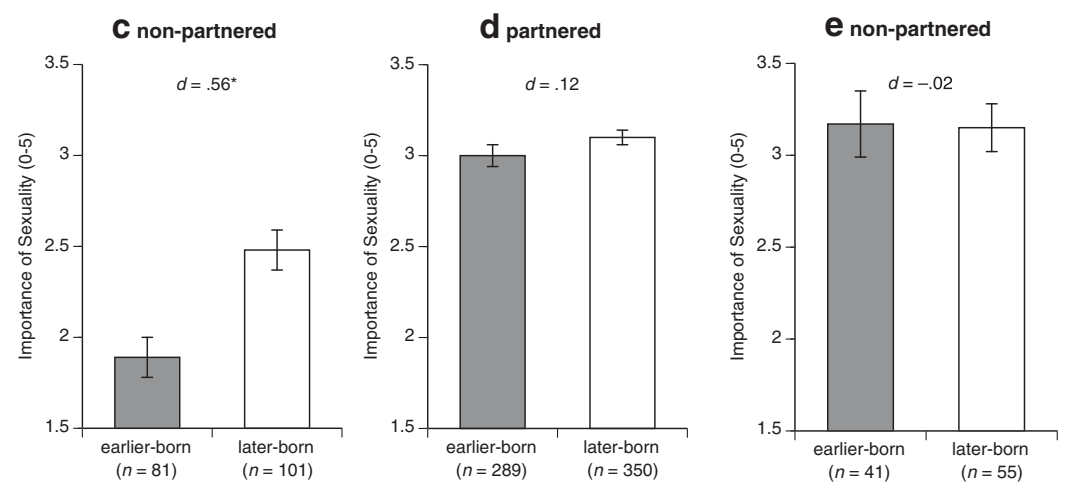

Men

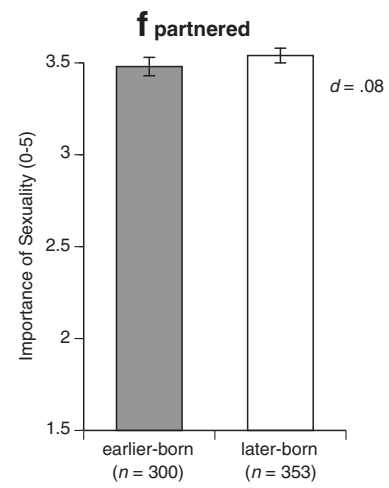

Note. Mean levels, standard errors, and effect sizes (Cohen's $d$ ) for perceived importance of sexuality, separately for women (upper left-hand panel a) and men (upper right-hand panel b) pooled across both LASA cohorts (data obtained in 1992-1993 and 2012-2013), and mean levels, standard errors, and effect sizes (Cohen's $d$ ) for perceived importance of sexuality by gender and relationship status, separately for the earlier-born (data obtained in 1992 -1993 ) and the later-born (data obtained in 2012-2013) LASA cohorts (lower panels c to f). The group sizes ( $n$ ) are indicated in the category labels.

Fig. 2 Gender Differences in Perceived Importance of Sexuality and Cohort Differences in the Gender-by-Partner-Status Interaction Effect of on Importance of Sexuality Among Adults in Late Midlife

their cohort interactions. To do so, we used data from the LASA obtained 20 years apart from two independent samples. Zero-order analyses revealed that later-born adults in their late midlife interviewed in 2012-2013 considered sexuality slightly more important than the earlier-born same-aged adults asked 20 years earlier, and they reported experiencing their sex lives as slightly less pleasant. When covarying for sociodemographic, physical health, and psychosocial factors, cohort differences in perceived importance of sexuality remained statistically significant at the $p<.05$ level, but cohort differences in enjoyment of sexuality were not statistically significant anymore. We discuss ways to interpret our findings and consider their implications.

\section{Cohort Differences in Late-Midlife Sexuality}

At the study population level, effects of cohort membership on both indicators of sexuality among adults in late midlife were small in size. To illustrate, for the importance of sexuality, the predictive effect of partner status was about four times larger than the population-level cohort effect ( $\beta \mathrm{s}=.23$ vs. .06). In contrast, moderate effect sizes of cohort membership were obtained for the perceived importance of sexuality within certain population segments, such as women without a partner and people with higher education also reporting fewer constraints. It is thus possible that the increases in the importance attributed to sexuality found at the zero-order level were mostly driven by historical changes in particular population segments. Because the significant three-way interaction effects with cohort membership were identified in an exploratory manner, the interpretation of such findings is purely speculative and should be treated with some caution. For women with no partner, one possible explanation is that they have particularly benefited from less pronounced gender disparities today (Shockley \& Shen, 2015), as well as changes in social norms and attitudes toward non-marital sexuality (Karraker et al., 2011) and late-life sexuality (Bouman et al., 2007) that have both become more permissive over the past decades. One could also speculate about the role of hormonal replacement therapy, which has been widely applied to reduce menopausal symptoms, but can also increase sexual desire in postmenopausal women (Cappelletti \& Wallen, 2016). It is possible that better sexual functioning in women constitutes one of the factors that contributed to the documented historical rise in 
Table 3 Standardized Betas $(\beta)$ from Regression Analyses of Enjoyment of Sexuality by Cohort and the Correlates

Enjoyment of sexuality

\begin{tabular}{|c|c|c|c|c|c|c|}
\hline \multirow[b]{2}{*}{ Predictors } & \\
\hline & Model 1 & Model 2 & Model 3 & Model 4 & Model 5 & Model 6 \\
\hline Cohort & $-.06^{*}$ & $-.07 *$ & $-.07 *$ & -.04 & -.04 & -.05 \\
\hline Age & - & $-.06^{*}$ & $-.06^{*}$ & -.05 & -.05 & $-.05^{*}$ \\
\hline Men & - & $.14^{* *}$ & $.15^{* *}$ & $.14 * *$ & $.16^{* *}$ & $.14 * *$ \\
\hline Education & - & .05 & .05 & .03 & .03 & .03 \\
\hline Salience of religion & - & - & $.06^{*}$ & $.06^{*}$ & .05 & $.06^{*}$ \\
\hline Multimorbidity & - & - & - & $-.06^{*}$ & -.05 & -.04 \\
\hline Functional limitations & - & - & - & $-.12 * *$ & $-.10 * *$ & $-.08 *$ \\
\hline Partnered & - & - & - & - & .04 & .04 \\
\hline Loneliness & - & - & - & - & $-.17 * *$ & $-.13 * *$ \\
\hline Depressive symptoms & - & - & - & - & - & -.05 \\
\hline Perceived constraints & - & - & - & - & - & $-.07 *$ \\
\hline Men $\times$ Partnered & - & - & - & - & .05 & .04 \\
\hline Cohort $\times$ Men & - & - & - & - & -.01 & -.01 \\
\hline Cohort $\times$ Partnered & - & - & - & - & .02 & .02 \\
\hline Cohort $\times$ Men $\times$ Partnered & - & - & - & - & -.02 & -.01 \\
\hline Total $R^{2}$ & $<.01$ & .03 & .04 & .06 & .10 & .10 \\
\hline$F$ & $4.89^{*}$ & $10.34 * *$ & $9.66^{* *}$ & $11.41 * *$ & $10.00^{* *}$ & $9.28 * *$ \\
\hline$(d f \mathrm{~s})$ & $(1,1257)$ & $(4,1257)$ & $(5,1246)$ & $(7,1244)$ & $(13,1241)$ & $(15,1231)$ \\
\hline
\end{tabular}

Note. $N=1258\left(N_{1992-1993}=531 ; N_{2012-2013}=727\right)$. Age centered at 60 years; all other predictors grand mean centered

$* p<.05$

$* * p<.01$

perceiving sexuality as an important aspect of one's life. The higher importance attributed to sexuality by more educated adults in late midlife who perceive fewer constraints may indicate that education and a high sense of control over one's life have been increasingly relevant resources for perceiving sexuality as an important area of this period in life. Historical change in importance of late-midlife sexuality might thus have been taking place gradually in the past decades, spearheaded by those educated individuals perceiving fewer constraints in their lives. One could also speculate that highly educated adults with a high sense of control are more prone to dissolve an unsatisfying relationship today than in the past (Finkel et al., 2015), and that historical increases in the importance of sexuality in this population segment are partially driven by partner changes.

Cohort effects in the enjoyment of sexuality indicated that later-born adults in late midlife experience their sex life as slightly less pleasant than their earlier-born peers. These effects, however, were minor in size at the population level and not reliably different from zero when relevant background factors were covaried. Independent of whether the effects are reliably different from zero or not, we note that, in our study sample, considering sexuality more important today than in the past did not go hand in hand with experiencing one's sex life as more enjoyable. It is possible that increasing importance of sex life creates new expectations toward sexuality. Similar to the developments of higher expectations toward one's marriage (Finkel et al., 2015), individuals might apply higher standards to sexuality today and expect both themselves and their partners to sexually perform in ways that cannot easily be fulfilled. Also, it is an open question whether the medical progress of the past decades has increased the frequency of sexual activity without necessarily improving the quality of sex life (Lee et al., 2015).

For both sexuality aspects, it is not possible to disentangle whether the cohort differences observed reflect actual changes in experiences and perceptions of sexuality, or the willingness to report on these. Given that the attitudes toward later-life sexuality have become more positive over the past decades (Beckman et al., 2008), it is possible that the willingness to reveal and share information about one's sex life has increased, too. Interpreted this way, higher importance of sexuality among later-born cohorts would reflect changes in the communication about late-midlife sexuality rather than in the actual value attributed to sexuality. Although the underlying mechanisms remain unclear, one could take our findings as 
contributing to the empirical evidence that older adults today hold, to some degree, different attitudes toward sexuality than in the past (DeLamater, 2012). Drawing from earlier reports (e.g., Mercer et al., 2013), we speculate that these findings likely mirror the shift toward the liberalization of social norms in Western societies.

\section{The Role of Socio-Demographic, Physical Health, and Psychosocial Factors}

Our findings corroborated and extended previous reports that socio-demographic, physical health, and psychosocial factors are relevant correlates of central sexuality facets in later life. To begin with, our finding that men in late midlife consider sexuality as more important and slightly more pleasant than same-aged women parallels findings obtained from samples of older adults (e.g., Müller et al., 2014; Syme et al., 2012) and qualifies these by partner status. Acknowledging that the menopause transition often undermines sexual functioning in women (Avis et al., 2017), we speculate that the importance postmenopausal women attribute to sexuality depends much more on relationship-oriented motivational processes than spontaneous (hormone-driven) sexual desire. Such motivational component of the female sexual response, including nonsexual motivation for sexual behavior, has already been postulated by Basson (2000) and shown in empirical studies for premenopausal women (Dewitte \& Mayer, 2018). After having become widowed or divorced, downgrading the importance of sexuality may thus serve as an adaptive selfregulatory strategy (Gott \& Hinchliff, 2003). More mechanism-oriented research is needed to disentangle biological from psychosocial factors affecting sexuality in later life, which can help better understand sexuality of postmenopausal women.

After covarying for socio-demographic and psychosocial factors, multimorbidity was significantly associated with neither perceived importance nor enjoyment of sexuality. These findings are in line with some of the earlier reports showing that, at the population level, individual differences in psychosocial functioning are often more decisive for sexuality than diagnosed illnesses or medications (DeLamater \& Sill, 2005; Kolodziejczak et al., 2019). Our finding that reporting more functional limitations was related to lower scores on both importance and enjoyment of sexuality is in line with the expectation that key quality of life outcomes are not so much shaped by the mere presence of a (medical) condition, but more so by the way this condition interferes with living an independent life. Also, engaging in sexual activity when people have one or another form of physical limitations, especially if these occurred recently, requires some degree of extra energy, which might be increasingly limited in late midlife.

We also found that perceiving fewer constraints in one's life was related to both considering sexuality more important and experiencing one's sex life as more pleasant. These findings enrich and complement earlier reports that perceiving more control over the sexual aspects of life is related to more frequent sexual activity (Lachman \& Firth, 2004) and higher quality of sex life in middle age (Forbes et al., 2017). Because of the cross-sectional nature of our study, it is not possible to address questions about temporal ordering or lead-lag associations. Thus, it is possible that perceiving lower constraints contributes to attributing higher importance to one's sex life and experiencing it as more pleasant. Likewise, valuing sexuality more and having a pleasant sex life may help people perceive fewer constraints in their lives. Finally, higher loneliness was not associated with perceived importance of sexuality, but it was related to lower enjoyment of sex life. Followup analyses including the emotional or social component of the loneliness scale as a correlate, respectively, revealed a substantively identical pattern of results as reported in the main text. This suggests that people in middle age who experience loneliness do not necessarily attribute less importance to sexuality, but being lonely is associated with how people feel about their sex lives. Again, our findings do not allow us to draw any inferences about the direction of such associations.

\section{Limitations and Outlook}

We note several limitations of our study measures, design, and sample. To begin with, as a limitation of our outcome measures, both aspects of sexuality examined here were assessed with a single item each. Thus, internal consistency as a measure of reliability cannot be computed and there is a risk of an unknown bias of individual interpretation. Despite the noted limitations, single-item measures are often used in research on sexuality. In several aspects, these have shown convergent validity with results obtained from more comprehensive measures, but lower test-retest reliability (e.g., for sexual satisfaction, Mark et al., 2014). It is thus important to corroborate and extend our findings with more comprehensive measures.

Among our predictor variables, salience of religion was operationally defined as a dichotomous variable and reflects endorsing strong faith as one of the most important aspects in life vs. not. Being to some degree religious, attending church, or other forms of religious involvement (Braam et al., 2004), was not analyzed in our study. We thus note that the results obtained for religiosity might have been restricted by the dichotomous variable type and may not generalize to other types of religiosity measures. We also note that all data used in our study were based on self-reports. Thus, an unknown selfreport bias, e.g., due to reference group comparisons (Dowd \& Todd, 2011) cannot be excluded. Given that the correlates examined did explain small to moderate shares of variance $\left(R^{2}=.10\right.$ to .22$)$, further predictors of importance and enjoyment of late-midlife sexuality should be considered. For 
example, it would be intriguing for future research to make use of behavioral data that were not available in the current study. For example, it is possible that if enjoyment declines because sexual problems emerge, then importance (in the sense of salience, tension between partners, etc.) might increase as a result. From a psychological perspective, examining differences in the attitudes toward aging and experiences of ageism might help explain additional portions of variance in the importance attributed to sexuality and the enjoyment of sex life (Estill et al., 2018). For cohort differences, we speculate that more positive views on aging among adults born later could enhance their experience of sexuality as an important and enjoyable area of life.

As limitations of the study design, we note that data on sexuality measures of interest were available for each cohort only at baseline assessment. Drawing from reports showing less steep age-related declines in psychosocial functioning among later-born older adults (for internal control beliefs: Gerstorf et al., 2019; for cognitive functioning: Gerstorf et al., 2011), we would speculate that age trajectories of the sexuality facets examined here probably also exhibit later onset and less steep rates of decline. Among the possible contributing factors could be medical progress of the past decades, which has been aimed to reduce the declines in sexual function often accompanying aging (e.g., low sexual desire among postmenopausal women; Cappelletti \& Wallen, 2016; erectile dysfunction after prostate cancer and radical prostatectomy; Salonia et al., 2015).

As a limitation of our sample, we acknowledge that our findings were derived from adults in late midlife (55 to 65 years) living in a highly developed Western nation. Although the study sample was selected to optimally represent the Dutch population, with respondents from both predominantly protestant, predominantly catholic, and largely secularized areas of the Netherlands (Hoogendijk et al., 2016), the data indicated a high degree of secularization: only 9 to $12 \%$ of the participants (in the later-born and earlier-born cohort, respectively) were endorsing strong faith as one of the most important aspects in life. It is thus an open question whether the historical changes documented here generalize to populations with a different cultural background. Because sexuality is shaped by socio-cultural circumstances, we would expect that societies fostering less permissive views on later-life sexuality (e.g., because of having not experienced the sexual revolution of the 1960s and 1970s) will exhibit a different pattern of secular changes. At the same time, it is an open question whether and how our findings generalize to other Western European and non-European nations, including the USA. For example, it will be intriguing to examine whether the historical rise in the importance of sexuality for nonpartnered Dutch women can also be found in other regions. Considering the interaction effects, we note that the small numbers in the category groups might have limited our statistical power and result in very few significant interaction effects with cohort membership.

Also, we acknowledge that only less than $1 \%$ of participants included in the analysis from both cohorts reported being in a non-marital same-sex relationship ( $n=15$, in total). Whereas same-sex marriages were legalized in the Netherlands in 2001, the LASA questionnaire on partner status remained unchanged since 1992 and allows to specify the sex of the non-marital partner, but not the sex of the spouse. Thus, it remains unclear how many participants in the laterborn cohort were in a same-sex marital relationship. Because of this limitation of our partner status measure, and due to a small number of respondents in non-heterosexual relationships, we were not able to account for sexual orientation in our analysis, or draw comparisons between heterosexual and non-heterosexual partnered individuals.

Finally, our findings on cohort differences in the importance and enjoyment of sexuality in late midlife should be corroborated and put into perspective in further studies, e.g., by examining if these results hold across other cohorts and periods. We note that our analyses do not allow concluding that there is a linear increase in the perceived importance of sexuality, with each successively born generation perceiving sex in midlife as more important than the preceding one. On the contrary, our follow-up analyses treating year of birth as continuous predictor (procedures applied as in other cohort studies, e.g., Drewelies, Deeg, et al., 2018) suggest an initial rise in the importance of sexuality for those born in the late 1930s and early 1940s, compared with those born in the late 1920s and early 1930s, followed by a plateau (see Online Supplementary Material). Several studies have recently reported historical declines in sexual frequency among adults in developed Western countries (e.g., Twenge et al., 2017; Wellings et al., 2019). It is an open question, how these and other reported changes in sex lives of young adults will impact their perceptions of sexuality in their 50s and 60s.

\section{Conclusions}

In closing, our analyses of cohort differences using the LASA data have revealed a small-sized and robust historical increase of the perceived importance of sexuality in late midlife at the population level that was mostly driven by moderately sized increases in the importance of sexuality in particular population segments, such as women who do not have a partner. After accounting for a number of further factors, cohort membership has not reliably predicted change in enjoyment of sexuality. Our findings contribute to the literature on sexuality in later life undergoing historical changes, with later-born adults in late midlife being more likely to report sexuality as important. More mechanism-oriented research is needed to 
better understand whether and how these changes are intertwined with other areas of life.

Funding Open Access funding enabled and organized by Projekt DEAL. The Longitudinal Aging Study Amsterdam (LASA) is financially supported by the Netherlands Ministry of Health, Welfare and Sports, Directorate of Long-Term Care. Financial support for the data collection in 2012-2013 was provided by the Netherlands Organization for Scientific Research (NWO) within the project New cohorts of young old in the 21st century, File Number 480-10-014.

\section{Compliance with Ethical Standards}

The LASA study was approved by the Medical Ethics Committee of the VU University Medical Center in Amsterdam, the Netherlands (IRB numbers 92/138 and 2012/361), and conducted based on the Declaration of Helsinki.

Open Access This article is licensed under a Creative Commons Attribution 4.0 International License, which permits use, sharing, adaptation, distribution and reproduction in any medium or format, as long as you give appropriate credit to the original author(s) and the source, provide a link to the Creative Commons licence, and indicate if changes were made. The images or other third party material in this article are included in the article's Creative Commons licence, unless indicated otherwise in a credit line to the material. If material is not included in the article's Creative Commons licence and your intended use is not permitted by statutory regulation or exceeds the permitted use, you will need to obtain permission directly from the copyright holder. To view a copy of this licence, visit http://creativecommons.org/licenses/by/4.0/.

\section{References}

Avis, N. E., Colvin, A., Karlamangla, A. S., Crawford, S., Hess, R., Waetjen, L. E., Brooks, M., Tepper, P. G., \& Greendale, G. A. (2017). Change in sexual functioning over the menopausal transition. Menopause, 24, 379-390. https://doi.org/10.1097/gme. 0000000000000770.

Bach, L. E., Mortimer, J. A., Vande Weerd, C., \& Corvin, J. (2013). The association of physical and mental health with sexual activity in older adults in a retirement community. The Journal of Sexual Medicine, 10, 2671-2678. https://doi.org/10.1111/jsm.12308.

Baltes, P. B., Cornelius, S. W., \& Nesselroade, J. R. (1979). Cohort effects in developmental psychology. In J. R. Nesselroade \& P. B. Baltes (Eds.), Longitudinal research in the study of behavior and development (pp. 61-87). Academic Press.

Basson, R. (2000). The female sexual response: A different model. Journal of Sex \& Marital Therapy, 26, 51-65. https://doi.org/10. 1080/009262300278641.

Baumeister, R. F. (2000). Gender differences in erotic plasticity: The female sex drive as socially flexible and responsive. Psychological Bulletin, 126, 347-374. https://doi.org/10.1037/0033-2909.126.3. 347.

Beckman, N., Waern, M., Gustafson, D., \& Skoog, I. (2008). Secular trends in self reported sexual activity and satisfaction in Swedish 70 year olds: Cross sectional survey of four populations, 19712001. BMJ, 337, a279. https://doi.org/10.1136/bmj.a279.

Beckman, N., Waern, M., Östling, S., Sundh, V., \& Skoog, I. (2014). Determinants of sexual activity in four birth cohorts of Swedish 70year-olds examined 1971-2001. The Journal of Sexual Medicine, 11, 401-410. https://doi.org/10.1111/jsm.12381.
Beier, K. M., Kossow, S., Zhou, Y., Kroll, F., Neumann, B., Konrad, A., Mundt, I., Steinhagen-Thiessen, E., Demuth, I., \& Pauls, A. (2019). The gap between desires and reality in sexuality of males and females aged 60 and over: Results from the Berlin Aging Study II (BASE-II). Sexologies., 29, e52-e62. https://doi.org/10.1016/j. sexol.2019.08.005.

Bouman, W. P., Arcelus, J., \& Benbow, S. M. (2007). Nottingham study of sexuality and ageing (NoSSA II). Attitudes of care staff regarding sexuality and residents: A study in residential and nursing homes. Sexual and Relationship Therapy, 22, 45-61. https://oi.org/10. 1080/14681990600637630.

Braam, A. W., Hein, E., Deeg, D. J. H., Twisk, J. W. R., Beekman, A. T. F., \& van Tilburg, W. (2004). Religious involvement and 6-year course of depressive symptoms in older Dutch citizens. Journal of Aging and Health, 16, 467-489. https://doi.org/10.1177/ 0898264304265765 .

Bronfenbrenner, U. (1993). The ecology of cognitive development: Research models and fugitive findings. In R. H. Wozniak \& K. W. Fischer (Eds.), Development in context: Acting and thinking in specific environments (pp. 3-44). Erlbaum.

Buczak-Stec, E., König, H.-H., \& Hajek, A. (2019). The link between sexual satisfaction and subjective well-being: A longitudinal perspective based on the German Ageing Survey. Quality of Life Research, 28, 3025-3035. https://doi.org/10.1007/s11136-01902235-4.

Cappelletti, M., \& Wallen, K. (2016). Increasing women's sexual desire: The comparative effectiveness of estrogens and androgens. Hormones and Behavior, 78, 178-193. https://doi.org/10.1016/j. yhbeh.2015.11.003.

Crimmins, E. M., Zhang, Y. S., Kim, J. K., \& Levine, M. E. (2019). Changing disease prevalence, incidence, and mortality among older cohorts: The health and retirement study. The Journals of Gerontology: Series A, 74(Supplement_1), S21-S26. https://doi. org/10.1093/gerona/glz075.

Cronbach, L. J. (1951). Coefficient alpha and the internal structure of tests. Psychometrika, 16, 297-334. https://doi.org/10.1007/ bf02310555.

De Jong Gierveld, J. (2004). Remarriage, unmarried cohabitation, living apart together: Partner relationships following bereavement or divorce. Journal of Marriage and Family, 66, 236-243. https://doi. org/10.1111/j.0022-2445.2004.00017.x.

De Jong Gierveld, J., \& Kamphuis, F. (1985). The development of a Rasch-type loneliness scale. Applied Psychological Measurement, 9, 289-299. https://doi.org/10.1177/014662168500900307.

De Jong Gierveld, J., \& Van Tilburg, T. G. (1999). Manual of the loneliness scale. Amsterdam, the Netherlands: Dept. of Social Research Methodology, Vrije Universiteit Amsterdam.

Deeg, D. J. H. (2007). Health and quality of life. In H. Mollenkopf \& A. Walker (Eds.), Quality of life in old age: International and multidisciplinary perspectives (pp. 195-213). Heidelberg: Springer Verlag. https://doi.org/10.1007/978-1-4020-5682-6_12.

Deeg, D. J. H., van Tilburg, T., Smit, J. H., \& de Leeuw, E. D. (2002). Attrition in the Longitudinal Aging Study Amsterdam. The effect of differential inclusion in side studies. Journal of Clinical Epidemiology, 55, 319-328. https://doi.org/10.1016/S08954356(01)00475-9.

DeLamater, J. (2012). Sexual expression in later life: A review and synthesis. Journal of Sex Research, 49, 125-141. https://doi.org/10. 1080/00224499.2011.603168.

DeLamater, J., \& Sill, M. (2005). Sexual desire in later life. Journal of Sex Research, 42,138-149. https://doi.org/10.1080/ 00224490509552267.

Dewitte, M., \& Mayer, A. (2018). Exploring the link between daily relationship quality, sexual desire, and sexual activity in couples. Archives of Sexual Behavior, 47, 1675-1686. https://doi.org/10. 1007/s10508-018-1175-x. 
Dowd, J. B., \& Todd, M. (2011). Does self-reported health bias the measurement of health inequalities in U.S. adults? Evidence using anchoring vignettes from the Health and Retirement Study. Journals of Gerontology: Series B. Psychological Sciences and Social Sciences, 66, 478-489. https://doi.org/10.1093/geronb/gbr050.

Drewelies, J., Agrigoroaei, S., Lachman, M. E., \& Gerstorf, D. (2018). Age variations in cohort differences in the United States: Older adults report fewer constraints nowadays than those 18 years ago, but mastery beliefs are diminished among younger adults. Developmental Psychology, 54, 1408-1425. https://doi.org/10. 1037/dev0000527.

Drewelies, J., Deeg, D. J. H., Huisman, M., \& Gerstorf, D. (2018). Perceived constraints in late midlife: Cohort differences in the Longitudinal Aging Study Amsterdam (LASA). Psychology and Aging, 33, 754-768. https://doi.org/10.1037/pag0000276.

Drewelies, J., Huxhold, O., \& Gerstorf, D. (2019). The role of historical change for adult development and aging: Towards a theoretical framework about the how and the why. Psychology and Aging, 34, 1021-1039. https://doi.org/10.1037/pag0000423.

Duncan, L. E., \& Agronick, G. S. (1995). The intersection of life stage and social events: Personality and life outcomes. Journal of Personality and Social Psychology, 69, 558-568. https://doi.org/ 10.1037/0022-3514.69.3.55.

Elder Jr., G. H. (1974). Children of the great depression: Social change in life experience. University of Chicago Press.

Estill, A., Mock, S. E., Schryer, E., \& Eibach, R. P. (2018). The effects of subjective age and aging attitudes on mid- to late-life sexuality. The Journal of Sex Research, 55, 146-151. https://doi.org/10.1080/ 00224499.2017.1293603.

Fileborn, B., Hinchliff, S., Lyons, A., Heywood, W., Minichiello, V., Brown, G., Malta, S., Barrett, C., \& Crameri, P. (2017). The importance of sex and the meaning of sex and sexual pleasure for men aged 60 and older who engage in heterosexual relationships: Findings from a qualitative interview study. Archives of Sexual Behavior, 46, 2097-2110. https://doi.org/10.1007/s10508-0160918-9.

Finkel, E. J., Cheung, E. O., Emery, L. F., Carswell, K. L., \& Larson, G. M. (2015). The suffocation model: Why marriage in America is becoming an all-or nothing institution. Current Directions in Psychological Science, 24, 238-244. https://doi.org/10.1177/ 0963721415569274.

Forbes, M. K., Eaton, N. R., \& Krueger, R. F. (2017). Sexual quality of life and aging: A prospective study of a nationally representative sample. The Journal of Sex Research, 54, 137-148. https://doi.org/ 10.1080/00224499.2016.1233315.

Galenkamp, H., Deeg, D. J. H., de Jongh, R. T., Kardaun, J. W. P. F., \& Huisman, M. (2016). Trend study on the association between hospital admissions and the health of Dutch older adults (1995-2009). BMJ Open, 6, e011967. https://doi.org/10.1136/bmjopen-2016011967.

Gerstorf, D., Drewelies, J., Duezel, S., Smith, J., Wahl, H.-W., Schilling, O. K., Kunzmann, U., Siebert, J. S., Katzorreck, M., Eibich, P., Demuth, I., Steinhagen-Thiessen, E., Wagner, G. G., Lindenberger, U., Heckhausen, J., \& Ram, N. (2019). Cohort differences in adult-life trajectories of internal and external control beliefs: A tale of more and better maintained internal control and fewer external constraints. Psychology and Aging, 34, 1090-1108. https://doi.org/10.1037/pag0000389.

Gerstorf, D., Ram, N., Hoppmann, C., Willis, S. L., \& Schaie, K. W. (2011). Cohort differences in cognitive aging and terminal decline in the Seattle longitudinal study. Developmental Psychology, 47, 1026-1041. https://doi.org/10.1037/a0023426.

Goldstein, I., Lue, T. F., Padma-Nathan, H., Rosen, R. C., Steers, W. D., \& Wicker, P. A. (1998). Oral sildenafil in the treatment of erectile dysfunction. New England Journal of Medicine, 338, 1397-1404. https://doi.org/10.1056/nejm199805143382001.
Gott, M., \& Hinchliff, S. (2003). How important is sex in later life? The views of older people. Social Science \& Medicine, 56, 1617-1628. https://doi.org/10.1016/s0277-9536(02)00180-6.

Grimm, K. J., Ram, N., \& Estabrook, R. (2016). Growth modeling: Structural equation and multilevel modeling approaches. Guilford Press.

Hoeymans, N., Wong, A., van Gool, C. H., Deeg, D. J. H., Nusselder, W. J., de Klerk, M. M. Y., van Boxtel, M. P. J., \& Picavet, H. S. J. (2012). The disabling effect of diseases: A study on trends in diseases, activity limitations, and their interrelationships. American Journal of Public Health, 102, 163-170. https://doi.org/10.2105/ ajph.2011.300296.

Hoogendijk, E. O., Deeg, D. J. H., Poppelaars, J., van der Horst, M., Broese van Groenou, M. I., Comijs, H. C., Pasman, H. R. W., van Schoor, N. M., Suanet, B., Thomése, F., van Tilburg, T. G., Visser, M., \& Huisman, M. (2016). The Longitudinal Aging Study Amsterdam: Cohort update 2016 and major findings. European Journal of Epidemiology, 31, 927-945. https://doi.org/10.1007/ s10654-016-0192-0.

Huisman, M., Poppelaars, J., van der Horst, M., Beekman, A. T. F., Brug, J., van Tilburg, T. G., \& Deeg, D. J. H. (2011). Cohort profile: The Longitudinal Aging Study Amsterdam. International Journal of Epidemiology, 40, 868-876. https://doi.org/10.1093/ije/dyq219.

Hülür, G., Drewelies, J., Eibich, P., Düzel, S., Demuth, I., Ghisletta, P., Steinhagen-Thiessen, E., Wagner, G. G., Lindenberger, U., \& Gerstorf, D. (2016). Cohort differences in psychosocial function over 20 years: Current older adults feel less lonely and less dependent on external circumstances. Gerontology, 62, 354-361. https:// doi.org/10.1159/000438991.

Infurna, F. J., Gerstorf, D., \& Lachman, M. E. (2020). Midlife in the 2020s: Opportunities and challenges. American Psychologist, 75, 470-485. https://doi.org/10.1037/amp0000591.

Iveniuk, J., \& Waite, L. J. (2018). The psychosocial sources of sexual interest in older couples. Journal of Social and Personal Relationships, 35, 615-631. https://doi.org/10.1177/ 0265407517754148

Karraker, A., DeLamater, J., \& Schwartz, C. R. (2011). Sexual frequency decline from midlife to later life. The Journals of Gerontology, Series B: Psychological Sciences and Social Sciences, 66, 502512. https://doi.org/10.1093/geronb/gbr058.

Kolodziejczak, K., Rosada, A., Drewelies, J., Düzel, S., Eibich, P., Tegeler, C., Wagner, G. G., Beier, K. M., Ram, N., Demuth, I., Steinhagen-Thiessen, E., \& Gerstorf, D. (2019). Sexual activity, sexual thoughts, and intimacy among older adults: Links with physical health and psychosocial resources for successful aging. Psychology and Aging, 34, 389-404. https://doi.org/10.1037/ pag0000347.

Kriegsman, D. M., Deeg, D. J., van Eijk, J. T., Penninx, B. W., \& Boeke, A. J. (1997). Do disease specific characteristics add to the explanation of mobility limitations in patients with different chronic diseases? A study in the Netherlands. Journal of Epidemiology \& Community Health, 51, 676-685. https://doi.org/10.1136/jech.51. 6.676 .

Lachman, M. E., \& Firth, K. M. (2004). The adaptive value of feeling in control during midlife. In O. G. Brim, C. D. Ryff, \& R. Kessler (Eds.), How healthy are we? A national study of well-being at midlife (pp. 320-349). University of Chicago Press.

Lasa-vu.nl. (2020). Retrieved July 22, 2020, from https://www.lasa-vu. $\mathrm{nl} /$ index.htm

Laumann, E. O., Paik, A., Glasser, D. B., Kang, J.-H., Wang, T., Levinson, B., Moreira, E. D., Nicolosi, A., \& Gingell, C. (2006). A cross-national study of subjective sexual well-being among older women and men: Findings from the Global Study of Sexual Attitudes and Behaviors. Archives of Sexual Behavior, 35, 143159. https://doi.org/10.1007/s10508-005-9005-3. 
Lee, D. M., Nazroo, J., O’Connor, D. B., Blake, M., \& Pendleton, N. (2016). Sexual health and well-being among older men and women in England: Findings from the English Longitudinal Study of Ageing. Archives of Sexual Behavior, 45, 133-144. https://doi.org/ 10.1007/s10508-014-0465-1.

Lee, D. M., Nazroo, J., \& Pendleton, N. (2015). Erectile dysfunction and phosphodiesterase type 5 inhibitor use: Associations with sexual activities, function and satisfaction in a population sample of older men. International Journal of Impotence Research, 27, 146-151. https://doi.org/10.1038/ijir.2015.4.

Liao, P. V., \& Dollin, J. (2012). Half a century of the oral contraceptive pill: Historical review and view to the future. Canadian Family Physician, 58, e757-e760.

Mark, K. P., Herbenick, D., Fortenberry, J. D., Sanders, S., \& Reece, M. (2014). A psychometric comparison of three scales and a single-item measure to assess sexual satisfaction. The Journal of Sex Research, 51,159-169. https://doi.org/10.1080/00224499.2013.816261.

McFarland, M. J., Uecker, J. E., \& Regnerus, M. D. (2011). The role of religion in shaping sexual frequency and satisfaction: Evidence from married and unmarried older adults. Journal of Sex Research, 48, 297-308. https://doi.org/10.1080/00224491003739993.

Mercer, C. H., Tanton, C., Prah, P., Erens, B., Sonnenberg, P., Clifton, S., Macdowall, W., Lewis, R., Field, N., Datta, J., Copas, A. J., Phelps, A., Wellings, K., \& Johnson, A. M. (2013). Changes in sexual attitudes and lifestyles in Britain through the life course and over time: Findings from the National Surveys of Sexual Attitudes and Lifestyles (Natsal). The Lancet, 382, 1781-1794. https://doi.org/10. 1016/s0140-6736(13)62035-8.

Müller, B., Nienaber, C. A., Reis, O., Kropp, P., \& Meyer, W. (2014). Sexuality and affection among elderly German men and women in long-term relationships: Results of a prospective population-based study. PLoS One, 9, e111404. https://doi.org/10.1371/journal.pone. 0111404

Orr, J., Layte, R., \& O’Leary, N. (2017). Sexual activity and relationship quality in middle and older age: Findings from the Irish Longitudinal Study on Ageing (TILDA). The Journals of Gerontology, Series B: Psychological Sciences and Social Sciences, 74, 287-297. https://doi.org/10.1093/geronb/gbx038.

Pearlin, L. I., \& Schooler, C. (1978). The structure of coping. Journal of Health and Social Behavior, 19, 2-21. https://doi.org/10.2307/ 2136319

Pettit, M., \& Hegarty, P. (2014). Psychology and sexuality in historical time. In D. L. Tolman, L. M. Diamond, J. A. Baumeister, W. H. George, J. G. Pfaus, \& L. M. Ward (Eds.), APA handbook of sexuality and psychology, Vol. 1. Person-based approaches (pp. 63-78). American Psychological Association. https://doi.org/10.1037/ 14193-003.

Pfeiffer, E., Verwoerdt, A., \& Wang, H.-S. (1969). The natural history of sexual behavior in a biologically advantaged group of aged individuals. Journal of Gerontology, 24, 193-198. https://doi.org/10.1093/ geronj/24.2.193.

Pfizer Inc. (2010). 2010 financial report. Retrieved July 22, 2020, from https://www.sec.gov/Archives/edgar/data/78003/ 000119312511048877/dex13.htm

Radloff, L. S. (1977). The CES-D scale: A self-report depression scale for research in the general population. Applied Psychological Measurement, 1, 385-401. https://doi.org/10.1177/ 014662167700100306

Rubin, G. S. (1998). Thinking sex: Notes for a radical theory of the politics of sexuality. In P. M. Nardi \& B. E. Schneider (Eds.), Social perspectives in lesbian and gay studies. A reader (pp. 143178). Routledge.

Salonia, A., Castagna, G., Capogrosso, P., Castiglione, F., Briganti, A., \& Montors, F. (2015). Prevention and management of post prostatectomy erectile dysfunction. Translational Andrology and Urology, 4, 421-437. https://doi.org/10.3978/j.issn.2223-4683. 2013.09.10.

Sarrel, P. M. (2000). Effects of hormone replacement therapy on sexual psychophysiology and behavior in postmenopause. Journal of Women's Health \& Gender-Based Medicine, 9, 25-32. https://doi. org/10.1089/152460900318830.

Schaie, K. W. (1965). A general model for the study of developmental problems. Psychological Bulletin, 64, 92-107. https://doi.org/10. 1037/h0022371.

Schick, V., Herbenick, D., Reece, M., Sanders, S. A., Dodge, B., Middlestadt, S. E., \& Fortenberry, J. D. (2010). Sexual behaviors, condom use, and sexual health of Americans over 50: Implications for sexual health promotion for older adults. The Journal of Sexual Medicine, 7, 315-329. https://doi.org/10.1111/j.1743-6109.2010. 02013.x.

Ševčíková, A., \& Sedláková, T. (2020). The role of sexual activity from the perspective of older adults: A qualitative study. Archives of Sexual Behavior, 49, 969-981. https://doi.org/10.1007/s10508019-01617-6.

Shield, A. D. J. (2020). The legacies of the stonewall riots in Denmark and the Netherlands. History Workshop Journal, 89, 193-206. https://doi.org/10.1093/hwj/dbz051.

Shockley, K. M., \& Shen, W. (2015). Couple dynamics: Division of labor. In T. D. Allen \& L. T. Eby (Eds.), The Oxford handbook of work and family (pp. 125-139). Oxford University Press.

Stewart, A. J., \& Healy, J. M. (1989). Linking individual development and social changes. American Psychologist, 44, 30-42. https://doi. org/10.1037/0003-066x.44.1.30.

Štulhofer, A., Hinchliff, S., Jurin, T., Carvalheira, A., \& Træen, B. (2018). Successful aging, change in sexual interest and sexual satisfaction in couples from four European countries. European Journal of Ageing, 16, 155-165. https://doi.org/10.1007/s10433-018-04921.

Suanet, B., \& van Tilburg, T. G. (2019). Loneliness declines across birth cohorts: The impact of mastery and self-efficacy. Psychology and Aging, 34, 1134-1143. https://doi.org/10.1037/pag0000357.

Syme, M. L., Klonoff, E. A., Macera, C. A., \& Brodine, S. K. (2012). Predicting sexual decline and dissatisfaction among older adults: The role of partnered and individual physical and mental health factors. The Journals of Gerontology, Series B: Psychological Sciences and Social Sciences, 68, 323-332. https://doi.org/10. 1093/geronb/gbs087.

Tavakol, M., \& Dennick, R. (2011). Making sense of Cronbach's alpha. International Journal of Medical Education, 2, 53-55. https://doi. org/10.5116/ijme.4dfb.8dfd.

Thomas, H. N., Hess, R., \& Thurston, R. C. (2015). Correlates of sexual activity and satisfaction in midlife and older women. The Annals of Family Medicine, 13, 336-342. https://doi.org/10.1370/afm.1820.

Twenge, J. M., Sherman, R. A., \& Wells, B. E. (2017). Changes in American adults' sexual behavior and attitudes, 1972-2012. Archives of Sexual Behavior, 44, 2273-2285. https://doi.org/10. 1007/s10508-015-0540-2.

Van Tilburg, T. G., Aartsen, M. J., \& van der Pas, S. (2014). Loneliness after divorce: A cohort comparison among Dutch young-old adults. European Sociological Review, 31, 243-252. https://doi.org/10. 1093/esr/jcu086.

Wellings, K., Palmer, M. J., Machiyama, K., \& Slaymaker, E. (2019). Changes in, and factors associated with, frequency of sex in Britain: evidence from three National Surveys of Sexual Attitudes and Lifestyles (Natsal). BMJ, 11525. https://doi.org/10.1136/bmj.11525.

Publisher's Note Springer Nature remains neutral with regard to jurisdictional claims in published maps and institutional affiliations. 